\title{
Development of Resilience Assessment Scale for Children admitted with Chronic Diseases
}

\author{
Kaur Manmeet \\ Assistant Professor, Chitkara School of Health Sciences, Chitkara University, Rajpura, Punjab, India
}

\begin{abstract}
Adolescence is a transitional stage of physical and psychological development that generally occurs during the entire period. Development of executive functions, or cognitive skills enables the control and coordination of thoughts and behaviour for appropriate functioning. Besides being sick there are certain related factors such as changing the health care team shifts, pain due to various rendering procedures, prolonged parental separation, peer detachment and loosing of self- esteem during the course of hospitalization. It is essential to assess the psychological domain of the adolescents while caring for the physical domain (chronic illness) as treatment modalities improve with psychological well-being. The objective of the study was to develop a scale for assessing resilience among children with chronicdiseases. Methodological research approach was used for development of an effective Resilience Assessment Scale for children admitted with chronic diseases. Study was done on 100 children aged 10-18 years admitted with chronic disease in MMIMS\&R Hospital,Mullana, Government Civil Hospital at Ambala and Karnal.From previous reviews of literature, expert's guidance and investigator's personal experience, a list of factors/domains were identified and compared with standardized Resilience s cales Modified Delphi technique was used for Content validation of Resilience assessment scale with seven experts Content validity was ascertained by expert's opin ion and was found to be 0.71. Cronbach's alpha and inter item correlation were used to measure internal consistency of the tool, coefficient alpha was 0.81.The range of rating score was 29-145 with the assumption that higher the scores, the greater the resilience. The recommendations for the future research can be Psychological interventions based on the comparison of resilience by resilience assessment scale by using different standardized scales in order to understand the lacking domains that are responsible for resilience and hence attain the maximum level of health.
\end{abstract}

Keywords: Resilience,Assessment scale, Children, Chronic Diseases

\section{Introduction}

\subsection{Background of the Study}

Growth is the progressive increase in the size of a child Development is progressive acquisition of various skills Psychological development, the development of cognitive, emotional, intellectual, and social capabilities and functioning over the course of the life span right from infancy through progressive ages. As the age progress with time development in a child takes place along with growth in physical, psychological, social, and spiritual domains as a whole. Child development refers to how a child becomes able to do more complex things as they cognitively gets older.

Around the age of 10-18 years, the theorists explained the overall development of the individual right from the childhood in aspects of cognitive development,psychosexual development, psychosocial development, moral development and development of faith respectively ${ }^{1}$. Chronic diseases are emerging to be an important aspect which needs close supervision in therapeutic as well as behavioural concept globally.Significant stress associated with risk for emotional and behavioural problems along with chronic diseases in adolescents interferes with adherence to treatment regimens and alters the psychological functioning. ${ }^{2}$ By the decade of the 1990's, researchers became increasingly focused on a phenomenon known as resilience. Resilience is the ability of the resilient to withstand or bounce back quickly from difficult conditions.

Besides being chronically sick there are certain related factors such as, pain due to various rendering procedures, changing health care team shifts, parentalseparation, peer detachment and loss of self-esteem during the course of hospitalization along with psychological deprivation as well. This psychological abilities and positive attitude among children goes on deteorating when the child goes through the pathway of chronic treatment. Coping during this(chronic) period and identifying the coping has become a major concern which is termed as "Resilience". Resilience is the word derived from "Resile" which means to "bounce or spring back"(re-"back"+salire-"to jump, leap;) Resilience is defined as resistance to illness, adaptation and thriving, the ability to bounce back or recover from stress. ${ }^{\text {" }}$

\section{Need of the Study}

During the past decade, resilience has increasingly become a focus of research in the behavioural and medical sciences. Measures that have been developed to assess "resilience" have focused the factors and resources that make them possible to achieve. ${ }^{2}$

Adolescent children suffering with a chronic illness experience a wide range of persistent stressors that can increase the risk of developing psychological problems. There is a need for chronically ill child to manage symptoms that introduce physical and lifestyle limitations, including restricted participation in school and sport, as well as treatment effects and the impact of incorporating ongoing treatment into daily activities. ${ }^{4}$ These factors limitthe spontaneity, create challenges for social relationships, and generate positive concerns about the future.

It is necessary to regain the lost activity, positive perception and functional outlooks and above all educational strengths and behavioural ratings among the children suffering from the chronic diseases. Very few studies and literatures have 


\section{International Journal of Science and Research (IJSR) \\ ISSN (Online): 2319-7064 \\ Index Copernicus Value (2015): 78.96 | Impact Factor (2015): 6.391}

reported to the development of tool to measure resilience and other related resources specifically for the chronic diseases in paediatric population. Children with chronic diseases undergo various health challenges such as inability to maintain nutritional balance, metabolic defects, physical and mental challenges. These challenges further pose a serious disability threat among children to follow their developmental deprivations and for their families to render those children the desired cooperation. ${ }^{3}$

So in this instance resilience assessment scale was designed up for the children aged 10-18 years suffering from chronic diseases in order to rule out the extent of the resilience acquired in relation to social domain, personal attributes, physical domain, psychological domain and also to gather various coping strategies used by the child to regain back the maximum potential for health and well-being. Nurses besides therapeutic regimen should also understand the psychological need and mental abilities of the child hospitalized with chronic diseasesin order to render quality and effective care and thus promote rehabilitation and resilience.

\section{Objective}

To develop a scale for assessing resilience among children with chronic diseases

\section{Methodology}

A methodological approach was used for the development of resilience assessment scale for the children admitted with chronic diseases. The study was conducted on 100 children aged 10-18 years with chronic diseases inPaediatric wards and Intensive care units of MMIMS\&R Hospital, Mullana, Government Civil Hospital at Ambala and Kalpana Chawla Government Hospital at Karnal.

Assent form was prepared in Hindi and the consent was taken from the parents of the study subjects regarding their willingness to participate in the research project. The purpose for carrying out research project was explained to the subjects and confidentiality of the study subjects was ensured.

\section{Phases of the Study}

\section{Phase 1: Preliminary Preparation}

This phase was completed in three steps:

\section{a) Review of literature}

Extensive review of literature was studied and the factors/domains affecting resilience were selected for the preparation of preliminary preparation of first draft.

\section{b) Generation of item pool}

An exhaustive list of the factors which plays an important role in attaining resilience among children with chronic diseases was prepared from literature review. Related factors contributing to Resilience such as personal attributes, physical domain, social domain, health related outcomes and various coping strategies used up by the child etc., were selected from the content and the items were pooled together.

\section{c) Preparation of Preliminary Draft}

The blue print of resilience assessment scale for children with chronic diseases was prepared. Descriptive view from the children with chronic diseases and their parents suffering with chronic diseases followed by qualitative analysis from the same helped to rule out their concerns in the diseases conditions and strategies to cope up with the same.

Phase 2: Validation of first draft and subsequent drafts. Validation of resilience assessment scale was done by four rounds of modified Delphi technique. Drafts were given to sevenexperts from the field of paediatric nursing and paediatric medicineand their suggestions were incorporated for the preparation of subsequent drafts. Modifications were made as per their suggestions and content validation and content validity index of the final draft of resilience assessment scale was calculated. The final draft of the resilience assessment scale contained 29 items related to Personal Attributes, Social Domain, Psychological Domain and Coping Strategies opted by the child during the journey of chronic illness. The range of rating score was 29 to 145.The scoring criteria for resilience is as under:

\begin{tabular}{|c|c|c|}
\hline S. No. & Levels & Range of Scores \\
\hline 1. & High Resilience & $107-145$ \\
\hline 2. & Moderate Resilience & $68-106$ \\
\hline 3. & Low Resilience & $29-67$ \\
\hline
\end{tabular}

\section{Phase 3: Pilot study}

The Resilience Assessment Scale was administered to 10 children with chronic diseases from MMIMS\&R hospital, Mullana after finalization of the second draft. The items were converted to Hindi and given to the children as selfadministered questionnaire. The result of the pilot study after first administration indicated that the language of items was clear but somewhere misinterpreted by the children. The investigator has to restate and re-comprehend the sentence for its easy understand ability for the child. The average time taken for responding to the components of the Resilience Assessment Scale from one patient was 30-40 minutes .So, in subsequent drafts, structured interview was opted that was comfortable for the patient as well as for the investigator.

\section{Phase 4: Final try out of Resilience Assessment Scale}

Resilience assessment scale was translated to Hindi for easy understanding of the child.Data was collected from patients with chronic diseases after translating the Resilience Assessment Scale from English to Hindi and further from Hindi to English for sentence Re-verification. The scale was administered to 100 children suffering with chronic diseasesin the month of August to October 2015. The average time taken in completing the Resilience Assessment Scale from one patient was 40-45 minutes.

Scoring criteria was modified for easy understanding and interpretation of the likert scale was:-

$5=$ All of the time ( $>8$ times/ 10 times $)$

$4=$ Most of the time (6-8 times/10 times)

$3=$ some of the time (4- 6 times/10 times) 


\section{International Journal of Science and Research (IJSR) \\ ISSN (Online): 2319-7064}

Index Copernicus Value (2015): 78.96 | Impact Factor (2015): 6.391

$2=$ A little of the time (2-4 times/10 times)

$1=$ None of the time $(<2$ times $)$

\section{Reliability}

\section{a) Internal consistency}

Data was analysed by using SPSS (version 21.0) .To find out internal consistency, reliability of present scale; the Cronbach's alpha was used. There were total 29 items in the scale and overall Cronbach's alpha coefficient of present scale was 0.81 . (Cronbach's alpha coefficient should be $>0.70) .{ }^{5}$ The resilience assessment scale for the patients suffering with chronic diseases was found to be highly reliable in terms of assessing the child's ability to spring back to previous state of well-being.

Table 1: Reliability analysis of resilience assessment scale, by using Cronbach Alpha

\begin{tabular}{|c|c|c|c|}
\hline S.NO & Items & $\begin{array}{l}\text { Corrected } \\
\text { Item-total } \\
\text { correlation }\end{array}$ & $\begin{array}{c}\text { Cronbach's } \\
\text { alpha if item } \\
\text { deleted }\end{array}$ \\
\hline 1. & $\begin{array}{l}\text { I like to play with my friends } \\
\text { whenever I feel. }\end{array}$ & 0.432 & 0.805 \\
\hline 2. & $\begin{array}{l}\text { I report any unusual sign or } \\
\text { symptom to my parents. }\end{array}$ & 0.458 & 0.803 \\
\hline 3. & $\begin{array}{c}\text { I take my favorite story books, } \\
\text { games along with me during } \\
\text { hospitalization. }\end{array}$ & 0.342 & 0.808 \\
\hline 4. & $\begin{array}{c}\text { I like to watch T.V, play video } \\
\text { games, mobile handling during } \\
\text { my free time. }\end{array}$ & 0.414 & 0.802 \\
\hline 5. & $\begin{array}{l}\text { I like to play outdoor games like } \\
\text { badminton, boll dosing, going a } \\
\text { new place to a market, fun park, } \\
\text { water park etc. with siblings and } \\
\text { neighbors. }\end{array}$ & 0.439 & 0.813 \\
\hline 6. & $\begin{array}{c}\text { I discuss my personal problems } \\
\text { with my teachers (disease } \\
\text { related). }\end{array}$ & 0.326 & 0.805 \\
\hline 7. & $\begin{array}{c}\text { I try to compensate my } \\
\text { absenteeism by studying extra } \\
\text { hours and with help of my class } \\
\text { mates. }\end{array}$ & 0.455 & 0.805 \\
\hline 8. & $\begin{array}{l}\text { I take help of my teachers in } \\
\text { completing my homework and } \\
\text { assignments. }\end{array}$ & 0.551 & 0.796 \\
\hline 9. & $\begin{array}{c}\text { I like to take part in co-curricular } \\
\text { activities (school games, drawing } \\
\text { competitions, and art and craft } \\
\text { workouts.) }\end{array}$ & 0.422 & 0.802 \\
\hline 10. & $\begin{array}{l}\text { I like to do my daily care } \\
\text { activities myself. }\end{array}$ & 0.344 & 0.805 \\
\hline 11. & $\begin{array}{c}\text { I feel hard to snap back when } \\
\text { something bad happens (sensitive } \\
\text { to situations). }\end{array}$ & 0.225 & 0.809 \\
\hline 12. & $\begin{array}{l}\text { I have a mentor with whom I } \\
\text { share my worries and feelings. }\end{array}$ & 0.374 & 0.814 \\
\hline 13. & $\begin{array}{c}\text { I know that I would get well as } \\
\text { early as I take my all medication } \\
\text { on time. . }\end{array}$ & 0.451 & 0.8 \\
\hline 14. & $\begin{array}{l}\text { I go for regular follow up as and } \\
\text { when advised. }\end{array}$ & 0.421 & 0.817 \\
\hline 15. & $\begin{array}{c}\text { I feel confident with parent's } \\
\text { presence during hospitalization. }\end{array}$ & 0.546 & 0.796 \\
\hline 16. & I sleep for 8-10 hours daily. & 0.568 & 0.796 \\
\hline 17. & $\begin{array}{l}\text { I feel confident with parent's } \\
\text { presence during hospitalization. }\end{array}$ & -0.039 & 0.801 \\
\hline
\end{tabular}

18. My past record in school gives confidence for newer achievements and challenges.

\begin{tabular}{|c|c|c|c|}
\hline 19. & $\begin{array}{l}\text { I try to see the positive side of the } \\
\text { happening situation. }\end{array}$ & 0.45 & 0.802 \\
\hline 20. & $\begin{array}{c}\text { I believe that there stands a } \\
\text { supernatural power that holds me } \\
\text { safe during my illness. }\end{array}$ & 0.629 & 0.798 \\
\hline 21. & I do meditation daily. & 0.06 & 0.813 \\
\hline 22. & $\begin{array}{l}\text { I like to be with myself as and } \\
\text { when troubles face me. }\end{array}$ & 0.319 & 0.806 \\
\hline 23. & I learn from my mistakes. & 0.318 & 0.806 \\
\hline 24. & $\begin{array}{c}\text { I come up with different ways to } \\
\text { handle a tough situation. }\end{array}$ & 0.418 & 0.802 \\
\hline 25. & $\begin{array}{l}\text { My parents feel pride for my } \\
\text { achievements. }\end{array}$ & 0.069 & 0.814 \\
\hline 26. & $\begin{array}{l}\text { I try to work hard more in a } \\
\text { situation when my teacher } \\
\text { expects best out of me for my } \\
\text { school work. }\end{array}$ & 0.451 & 0.801 \\
\hline 27. & $\begin{array}{c}\text { My family helps me whenever I } \\
\text { need them. }\end{array}$ & 0.032 & 0.814 \\
\hline 28. & $\begin{array}{l}\text { I try to work out problems by } \\
\text { talking or writing about them. }\end{array}$ & 0.36 & 0.808 \\
\hline 29. & $\begin{array}{l}\text { I think myself as a strong person } \\
\text { to deal with difficulties. }\end{array}$ & 0.329 & 0.806 \\
\hline
\end{tabular}

\section{b) Equivalence of resilience assessment scale:}

\section{Inter-Rater Reliability}

Inter Rater reliability was calculated on 10 patients by Cohen's kappa and was found to be 0.76 for the resilience assessment scale for the children suffering from chronic diseases.

\section{c) Stability of resilience assessment scale:}

\section{Test Retest Reliability}

During the final try out of the resilience assessment scale, the test retest group was formed from 10 patients suffering with chronic diseases. The tool was coded with order number 1 to 10.The patients were interviewed with Resilience Assessment Scale. After 5 days, same patients were interviewed with same code number. Karl Pearson test was applied. The total instrument test retest reliability was 0.80.(normal value of Test Retest reliability is .70-1). ${ }^{5}$

\section{Validity}

\section{i. Face Validity}

The practical tool in the assessment of face validity is an expert panel; by seeing the tool majority of experts suggested that all the domains contributing in promotion of resilience are well organized and structured. Thus, the face validity of the tool was considered good.

\section{ii. Content validity}

Content validity Performa was circulated to the panel of experts which was having 29 items and experts were asked to evaluate the items. Content validity of resilience assessment scale was checked by calculating the content validity index (CVI) through the Performa filled by the experts. Content validity index came out to be 0.71 (values of CVI higher than 0.78 are considered having good content validity $)^{5}$. 


\section{International Journal of Science and Research (IJSR) \\ ISSN (Online): 2319-7064}

Index Copernicus Value (2015): 78.96 | Impact Factor (2015): 6.391

\section{iii. Concurrent validity}

Wagnild and Young Resilience scale (Variable 1)was used as a Gold Standard because the items in the scale are similar to the items in the Resilience Assessment Scale (Variable 2)and the scale was also used for the adolescents.Pearson correlation between the resilience assessment scale and Wagnild and Young resilience scale,was calculated for concurrent validity. Data was calculated from 100 patients with the help of both the tools. The value of Pearson correlation came out to be $0.80^{5}$; signifying that there was positive correlation between both the tools.



Figure 1: Positive correlation showing relationship between Wagnild and Young resilience scale and Resilience Assessment Scale for children suffering with chronic diseases..

\section{a) Predictive validity}

It reveals Sensitivity, Specificity, Positive Predictive Value (PPV), Negative Predictive Value $(\mathrm{NPV})^{5}$ tests of the Resilience Assessment Scale for prediction of resilience

\section{iv. Construct Validity :}

\section{Factor analysis}

Exploratory factor analysis was used in identifying the key factors of resilience assessment scale. The value for Kaiser Meyer Olkin (KMO) and Bartlett's test of sphericity was applied to assess the tool for its eligibility for carrying out factor analysis statistically. The value for Kaiser -Meyer olkin was $<.60$ and whereas $p$ value of Bartlett's test of Sphericity was $>0.05^{5}$, which was not significant.it means that the data was not suitable for factor analysis.so, factor analysis findings were not considered in the resilience assessment scale for children with chronic diseases.

\section{Discussion}

The investigator developed the Resilience Assessment scale for the children suffering with chronic diseases keeping in mind the need of understanding the psychological aspect of the child with other therapeutic treatment modalities. The Resilience Assessment scale constituted various domains/factors that affect the resilience among the children with chronic diseases during the course of the illness. The Resilience Assessment scale consisted 29 items including personal attributes, social domain, psychological domain and coping strategies opted by the child during the journey of chronic illness. Child and youth resiliency measure, CYRM among children with chronic diseases, and these were calculated at each score from 78 to 128 .Senstivity ranged from 0 to $100 \%$.At a cut-off point of $>102$, the best balance between the sensitivity and specificity was achieved ,i.e. Sensitivity was $90.48 \%$,Specificity was $66.67 \%$,Positive Predictive Value was $86.4 \%$ and Negative Predictive Value was $75 \%$.Since cut -off point of the tool was $>102$,patients who are having a score $\geq 102$, are at level of achieving Resilience.

Table 2: Sensitivity, Specificity, Positive Predictive Value (PPV), Negative Predictive Value (NPV) Tests

\begin{tabular}{|c|c|c|c|c|}
\hline $\begin{array}{c}\text { Cut Off Point } \\
\text { Total Score }\end{array}$ & $\begin{array}{c}\text { Sensitivity } \\
\%\end{array}$ & $\begin{array}{c}\text { Specificity } \\
\%\end{array}$ & $\begin{array}{c}\text { PPV } \\
\%\end{array}$ & $\begin{array}{c}\text { NPV } \\
\%\end{array}$ \\
\hline$\geq 59$ & 100 & 0 & 70 & 76 \\
\hline$>78$ & 100 & 11.11 & 72.4 & 100 \\
\hline$>81$ & 100 & 22.22 & 75 & 100 \\
\hline$>93$ & 100 & 33.33 & 77.8 & 100 \\
\hline$>96$ & 100 & 44.44 & 80.8 & 100 \\
\hline$>98$ & 100 & 55.56 & 84 & 100 \\
\hline$>100$ & 95.24 & 55.56 & 83.3 & 83.3 \\
\hline$*>102$ & 100 & 100 & 86.4 & 75 \\
\hline$>104$ & 80.95 & 66.67 & 85 & 60 \\
\hline$>105$ & 76.19 & 77.78 & 88.9 & 58.3 \\
\hline$>106$ & 71.43 & 77.78 & 88.2 & 53.8 \\
\hline$>108$ & 57.14 & 88.89 & 92.3 & 47.1 \\
\hline$>110$ & 52.38 & 88.89 & 91.7 & 44.4 \\
\hline$>111$ & 47.62 & 100 & 100 & 45 \\
\hline$>112$ & 42.86 & 100 & 100 & 42.9 \\
\hline$>114$ & 38.1 & 100 & 100 & 40.9 \\
\hline$>116$ & 33.33 & 100 & 100 & 39.1 \\
\hline$>121$ & 23.81 & 100 & 100 & 36 \\
\hline$>122$ & 19.05 & 100 & 100 & 34.6 \\
\hline$>125$ & 14.29 & 100 & 100 & 33.3 \\
\hline$>127$ & 9.52 & 100 & 100 & 32.1 \\
\hline$>128$ & 0 & 100 & 80 & 30 \\
\hline
\end{tabular}

was developed for the adolescents which included personal attributes, community domain, peer domain and contextual connectedness.

Wagnild and Young developed a 25 item Resilience Scale, $\mathrm{RS}$ for the adolescent children to check for the resilience achieved in overall domains including personal competence and acceptance of self and life.

Also, Resiliency tool was developed for chronic diseases. Components of the questionnaire were in three domains; interpersonal characteristics, characteristics of coping, and intrapersonal characteristics. Factor analysis has shown five factors; positive self-understanding, self-reliance, resourcefulness, perception of positive family relationships, and intimacy. Investigator calculated the internal consistency of resilience assessment scale and found it to be highly reliable that is 0.81.Similarly, Wagnild and Young developed a resilience scale and similarly calculated internal consistency and was also found to be reliable that is 0.91 .

A study conducted on development of tool calculated the concurrent validity by correlating with other resilience measures and found it to have positive correlation. Also, the correlation of Resilience assessment scale was found to be highly correlated with another measure of resilience.

\section{Volume 6 Issue 1, January 2017




\section{Conclusion}

The conclusion was drawn from the findings of the study that the resilience assessment scale consists of total 29 items including personal attributes, social domain, psychological domain and coping strategies opted by the child during the journey of chronic illness.

The resilience assessment scale developed by the investigator is valid and reliable and can be used effectively to predict the patients for resilience in chronic diseases.

\section{References}

[1] Marlow R. Dorothy, Redding A. Barabara. Textbook of Paediatric Nursing. $6^{\text {th }}$ Edition. Elsevier India pvt.ltd.2005. p 163-180

[2] Newacheck P et.al Prevalence and impact of multiple childhood chronic illnesses. Journal of Pediatrics. [Internet].[Cited in 1994].124:40-84 available from:http://www.ncbi.nlm.nih.gov/pubmed/ 7506774

[3] Marlow J. et.al: The psychosocial wellbeing of children with chronic disease, their parents and siblings. [Internet].[Cited in 2006].32:19-31. Available from http://www.ncbi.nlm.nih.gov/pubmed/16398788

[4] Alderfer, M.et.al Evidence-based assessment in pediatric psychology: Journal of Pediatric Psychology, [Internet].[Cited in 2007] 33(9), 1046-1061.available from www.ncbi.nlm.nih.gov/pubmed/17728305.

[5] Polit and beck, Nursing Research. Generating and assessing evidence for nursing practice. $9^{\text {th }}$ edition. wolters Kluwer private limited.2012:58-59,105$107,132,248-250,337-339,371,556-583$. 